\title{
Rock magnetic and micro-morphological analysis on snow deposits: recognition of anthropogenic origin of particulate matter in urban and wilderness areas (central Italy)
}

\author{
Laura Alfonsi*, Patrizia Macrì, Manuela Nazzari \\ Istituto Nazionale di Geofisica e Vulcanologia, Roma, Italy
}

Article history: received June 16, 2020; accepted February 17, 2021

\begin{abstract}
Low field magnetic susceptibility and other rock magnetic analyses are applied to inspect the magnetic nature of solid residuals in snow samples collected in downtown Rome and in two Natural Parks in central Italy. Field emission scanning electron microscope and energy dispersive spectroscopy (FESEM-EDS) analyses are utilized to reveal the nature of Fe-rich particles and discriminate their anthropogenic origin. The results indicate that magnetite $\left(\mathrm{Fe}_{3} \mathrm{O}_{4}\right)$ is the main magnetic carrier in almost all samples and that the variations in concentration are directly associated with local sources of particulate matter (PM) from anthropogenic pollution related to automotive circulation in both environments. Magnetic minerals of other provenance are found as accessories. The snow deposits revealed to be an efficient neutral tool for fine particle collections, also in environments characterized by different concentration and source of pollutants.
\end{abstract}

Keywords: Rock magnetism; FESEM-EDS; Particulate matter; Snow sampling; Pollution.

\section{Introduction}

In the recent past a series of studies concerning snow analyses demonstrated the capacity of snowflakes to capture pollutants from the atmosphere in region characterized by cold climatic conditions [e.g. Engelhard et al., 2007; Nazarenko et al., 2017]. Other study in urban environments highlighted the ability of snow sampling to monitor the level of airborne pollutants which originate from road traffic [Viklander, 1996; Viskari et al., 1997; Elik, 2002]. Bucko et al. [2011] tested the snow surveying as a tool to collect and characterize the magnetic physicochemical aspects of vehicle-derived particles. The analysis of snowmelt water and snow-dust was successful used in industrial environment [Boom and Marsalek, 1988; Westerlund and Viklander, 2006; Muller et al., 2020]. Then, the snow sampling was employed as a primary source of information for environmental data in areas where no dedicated monitoring systems were available, especially in those regions where the snow characterizes the majority of the atmospheric precipitation [Gabrielli et al., 2008; Kuoppamaki et al., 2014].

In both wilderness unexploited areas and urban sites, others tools but snow are commonly employed in pollution assessment studies. In particular, biomonitoring through lichens and tree leaves is widely exploited in magnetic 


\section{Laura Alfonsi et al.}

environmental studies [Moreno et al., 2003; Kodnick et al., 2017; Paoli et al., 2017; Winkler et al., 2019, 2020; Mariè et al., 2020]. Lichens demonstrated to be an efficient bioindicators of air quality in different environment [Conti and Cecchetti, 2001; Abas, 2021].

In this study we applied snow sampling techniques for air pollution analysis in natural and urban locations, with the aim to characterize and compare the anthropogenic contribution to the magnetic fraction of particulate matter (PM). PM is a term commonly employed to describe a mixture of solid particles and liquid droplets in the air, which vary greatly in size, composition, and origin. Iron oxides minerals, as magnetite, are present in atmospheric PM, with dimensions ranging from a few nanometers to several micrometers. Because of this, iron rich pollutants may have adverse health effects, when inhaled breathing and enter into the respiratory system, penetrating through the cell tissue and into the central nervous system [e.g. Oberdörster et al., 2004; Gierè, 2016]. In regard to the human health effects the published studies show the effects of magnetite on brain and respiratory system, highlighting how the presence of magnetite in the brain may be linked to several neurodegenerative diseases, including Alzheimer [Pankhurst et al., 2008]. Electron microscope images on human brain tissue evidenced the presence of magnetite nanoparticles of two different type: spherical and euhedral, suggesting a different origin for the nanoparticles, i.e from air pollution and of biogenic origin [Maher et al., 2016].

In this respect, it seems relevant to investigate the level of iron rich pollutants in areas where no automatic system of air quality control are active. On this aim, exploiting the snow as passive receptor tool, a snow sampling campaign was set up to investigate the possible contribution of anthropogenic magnetic particles to the total airborne PM. The analysis was carried out in an urban district and in some natural unexploited environments, utilizing magnetic, micro-textural and micro-chemical analyses. The whole set of rock magnetic and electron microscopy investigations (FESEM-EDS) was designed to outline the magnetic mineral content retained by the snow, and possibly discriminate among the fraction directly associated with the anthropogenic contribution with respect to the natural dust content. To achieve this, analyses of rock magnetic properties were conducted on the solid residual obtained from the snow samples in order to define the amount of the Fe-rich magnetic particles; these analyses, coupled with morphological and qualitative chemical studies, allowed to define the origin, shape and characters of the magnetic particles observed. In particular, the research intended to explore the magnetic particles contribution to the atmospheric PM and their origin, in different environments, employing the snow as a neutral micro-particle collector.

\section{Sampling and Methods}

\subsection{Paleomagnetism and rock magnetism}

Snow samples were collected during the 2012 winter season in Rome urban area and in the late spring of 2016 in wilderness reserve parks in Central Apennines (Gran Sasso and Monti della Laga National Park, Velino-Sirente regional Park, Figure 1). In the lapse of time between the two sampling campaigns the characteristic of the environment at the sites and/or the level of possible air pollutants did not undergo any changes (ARPA, www.arpalazio.gov.it and www.artaabruzzo.it). During this time, in fact, the distinctive aspects of the different sampling localities did not experienced changes in the meteorological seasonal variability. In addition, the amount of vehicles circulating in both areas is proven to be quite constant thorough the years considered in this study (ANAS, www.stradeanas.it/it/le-strade/osservatorio-del-traffico).

The Rome area samples were collected a week after a quite uncommon snowfall occurred in February 2012. On that occasion, the low outside temperatures allowed maintenance of the snow on the road side, preventing melting before being sampled. These samples (Rome, RM; Figure 1) come from different and close snow patches located along a high traffic roadside in Via di Vigna Murata, in midtown Rome. A volume of ca. $1800 \mathrm{~cm}^{3}$ of snow was obtained and let melt in a plastic recipient at room temperature. For the urban samples, the solid material utilized for measurements was obtained simply straining the water out after the solid fraction decanted. Eventual residuals, like seed or small asphalt street materials, were hand separated from the rough-drained fraction. At the end of the process, 30 grams of dust material was obtained.

The samples collected in the wilderness areas come from mountain environments that, on seasonal basis, are affected by heavy snow falls. All the samples were picked during the late spring season (from April to early July 
2016), allowing the snow to be sufficiently exposed to the atmospheric particulate. These snow samples belong to rural areas or fall in ski resort areas exploited for leisure purposes (Campo Felice, CF; Sirente, SR; Ovindoli, OV; Gran Sasso GR; Campo Imperatore, CI; Figure 1). In particular, three sampling sites are positioned along skiing mountain trails (GR, SR, CI) and two samples in partially urbanized ski winter areas and resorts (OV, CF). For each site from 8 to 12 snow samples were collected in plastic bottles of 1 liter volume $\left(1200 \mathrm{~cm}^{3}\right.$ of snow, Figure 2a-c). The snow was let melt at room temperature and then filtered using a filtration flask made up assembling a Buchner funnel to a vacuum pump (Figure 2c). To retain the solid fraction, the Buchner funnel was coupled with Whatman42 quantitative paper filters (cotton filters, ash less, particle retention $2.5 \mu \mathrm{m}$ ). Then, the solid fraction was retrieved from the paper filter once dried. Samples of soil were also locally taken and analyzed, in order to have details on the background rock magnetic values characteristic of each sampling area.

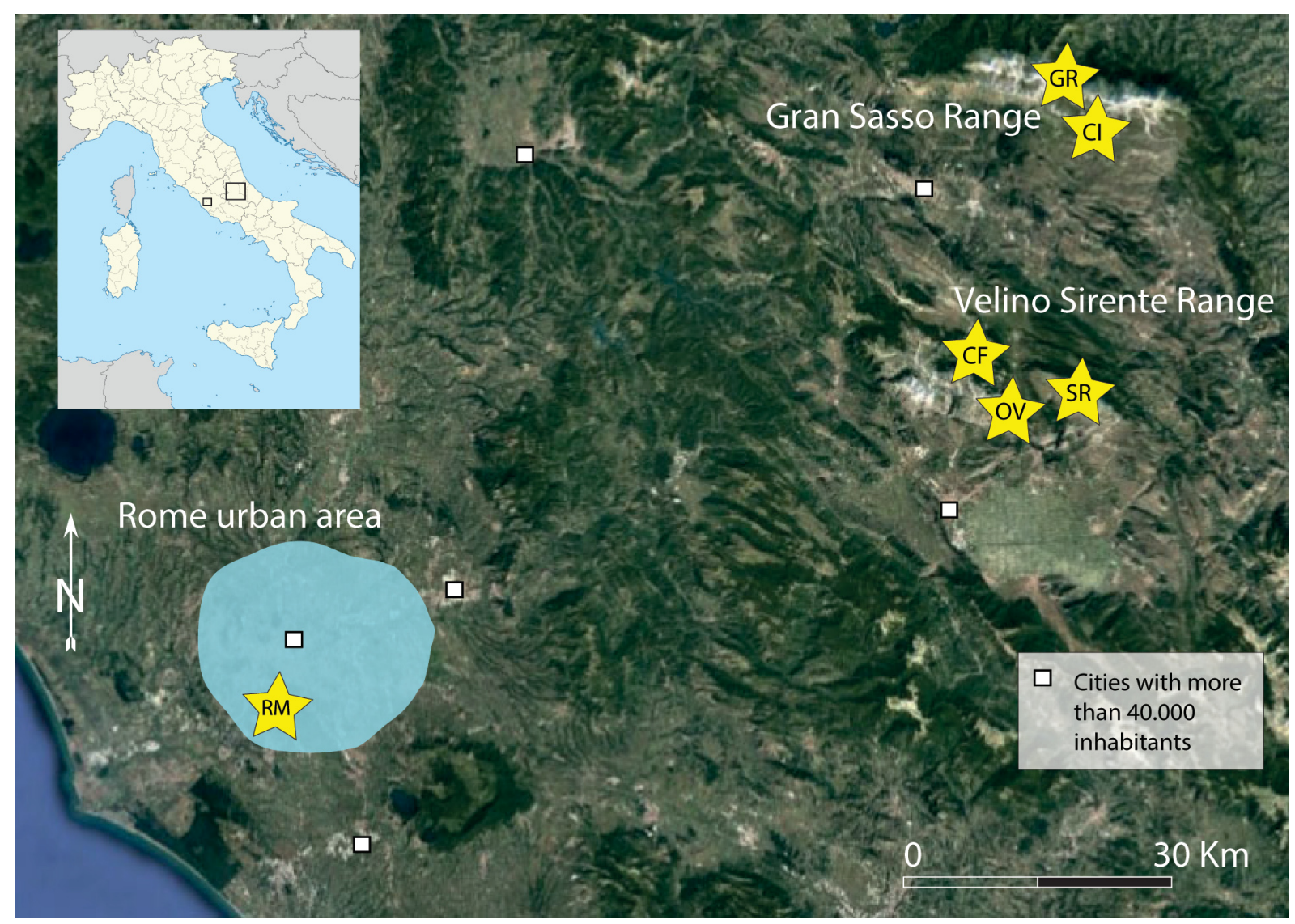

Figure 1. Location of the sampling sites, their relative position in the Central Apennine area and urban Rome is shown. The pale blue area highlights the boundary of the urban city of Rome. Squares locates the cities with more than 40.000 inhabitants.

A total of 72 samples were obtained after the draining process, 44 residual powder samples and 28 employed paper filters. All the samples were put into $2 \times 2 \times 2 \mathrm{~cm}$ standard plastic boxes to proceed in the laboratory for rock magnetic analyses.

Following the available knowledge of the "a priori" level of pollutants exposure, at the sampling locality (e.g. ANAS), we grouped sample sites in three classes characterized by: i) high automotive circulation (urban site, with nearly 50.000 circulating vehicles per day, RM); ii) sporadic and periodic circulation, (ski resort area with seasonal peak of vehicles circulation with no more than 3.500 vehicles per day during the winter spring season, CF, OV); ii) truly wilderness protected area (with a very sporadic or negligible circulation, GR, SR). 


\section{Laura Alfonsi et al.}

Low field mass magnetic susceptibility $\left(\chi \mathrm{m}^{3} \mathrm{~kg}^{-1}\right)$ was measured in the paleomagnetic laboratory of the Istituto Nazionale di Geofisica e Vulcanologia in Rome, with an AGICO Kappabridge system, KLY-2 model. Before any measurement, the weight and the magnetic susceptibility of each empty plastic box container was determined and the values were algebraically subtracted to those of the corresponding sample. Regarding the clean paper filters employed, their magnetic susceptibility resulted to be negligible. At the end of the low field magnetic susceptibility measurements, 10 powder samples (out of the 44 ) were rejected for further analyses, because of the very low values of their magnetic susceptibility.

Continuously monitored temperature dependence of magnetic susceptibility (until $700{ }^{\circ} \mathrm{C}$ ) was measured using AGICO MFK1-FA Kappabridge equipped with a CS-3 furnace in order to identify the Curie temperature of the magnetic minerals [cfr. Petrovský and Kapicka, 2006].

A MicroMag magnetometer (Princeton Measurements Corp. Model 2900 MicromagTM), was employed to examine the hysteresis properties, i.e., coercive force (Bc), saturation magnetization (Ms), and saturation of remnant magnetization (Mrs) with a maximum applied field of $1 \mathrm{~T}$. Coercivity of remanence (Bcr) was derived from backfield remagnetization curves.

An anhysteretic remanent magnetization (ARM) was imparted to the whole set of samples using a bias field (DC) of $0.05 \mathrm{mT}$ and a peak-alternating field (AF) of $100 \mathrm{mT}$, employing a 2G Enterprise magnetometer with an in-line AF demagnetizer and DC field solenoid. The ARM intensity of the samples was measured and stepwise demagnetized using AF peaks of 10, 20, 30, and $40 \mathrm{mT}$.

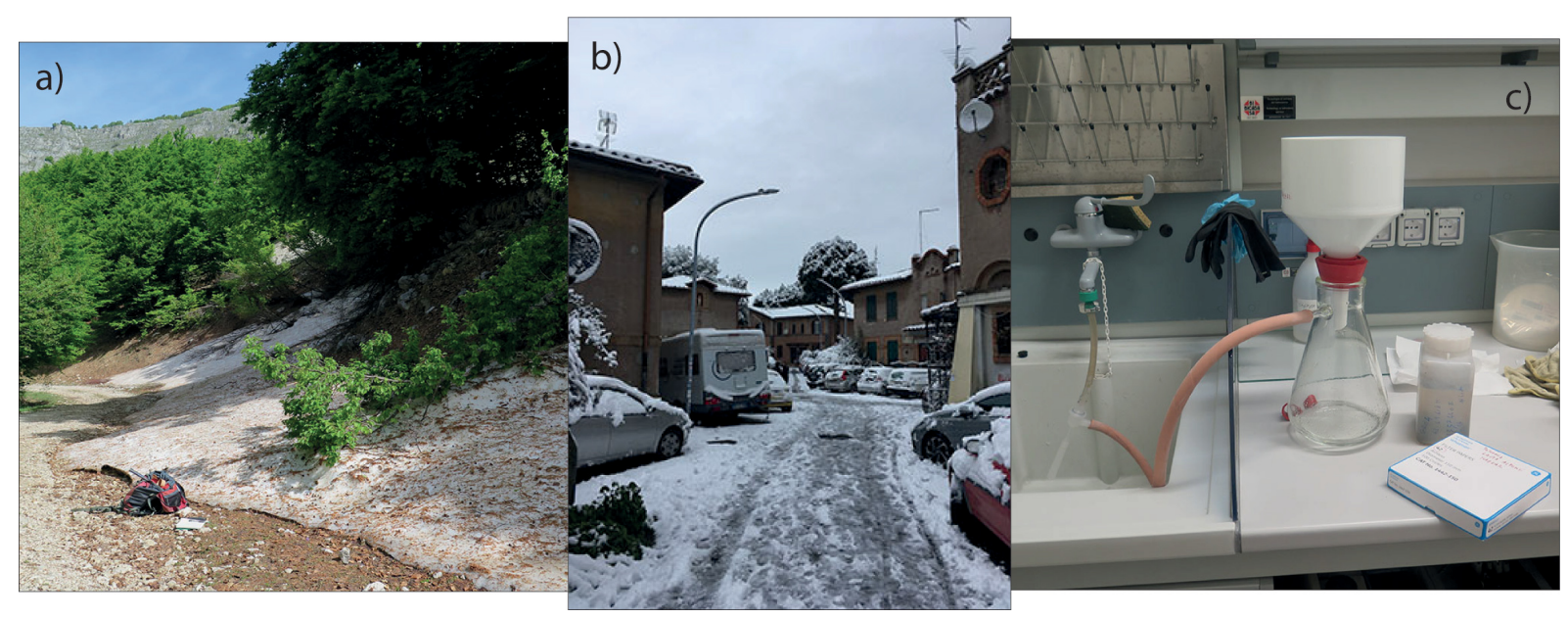

Figure 2 a) sampling site along a mountain trek trail; b) sampling site in urban area; c) filtration equipment: flask, Buchner funnel, the vacuum pump, the Whatman42 quantitative paper filters employed to retain the solid fraction from the melted snow.

\subsection{Micro-Morphological analyses instruments and methods}

Qualitative microscope observations were performed on selected samples (Table 2), the selection was made on the basis of the rock magnetic analysis results and the preference was given to samples showing high magnetic susceptibility values. These analyses allowed a qualitatively characterization of the chemical content and inspection of the morphological aspects of the magnetic fraction, endorsing a further discrimination among the natural and anthropogenic Fe-rich fraction.

The size and shape of individual particles were observed using a JEOL JSM 6500F Field Emission (Schottky type) Scanning Electron Microscope (FESEM, resolution $1.5 \mathrm{~nm}$ at $15 \mathrm{kV}$ operating voltage), equipped with backscattered electron detector and Energy Dispersion System (EDS, JEOL HYPERNINE, $133 \mathrm{eV}$ resolution) microanalysis. Before FESEM observation, the samples were carbon-coated using a JEOL JEC-530 Auto Carbon Coater. The microscope working distance was $10 \mathrm{~mm}$, with an accelerating voltage of $15 \mathrm{kV}$. 


\section{Results and discussion}

The values of the magnetic parameters measured are summarized in Table 1 and allowed the identification of the dominant magnetic minerals in the snow samples. In general, the distribution of the low field mass susceptibility allows the classification of the samples based on the level of generic source of anthropogenic pollutants [for a review see Sagnotti et al., 2009]. The mass specific magnetic susceptibility distribution indicates an evident relation with the closeness of great urban area (see circle dimension of sampled sites on Figure 3) and, as expected, the maximum values are observed at sites close to high traffic roads and urban clusters. Among the positive values, for the magnetic susceptibili ties, the higher is reached for samples in downtown Rome (i.e. $1055 \times 10^{-8} \mathrm{~m}^{3} \mathrm{~kg}^{-1}$ ) while the lower value is found for the ones of the mountain range (GR09, 11, $12 \times 10^{-8} \mathrm{~m}^{3} \mathrm{~kg}^{-1}$ Figure 3). This data are an indication for the distribution of concentration of magnetic pollutants in sampling sites.

The hysteresis loops of the whole set of samples show very narrow aspects (Figure 4, column A), in general indicative of Multi Domain (MD), Pseudo Single Domain (PSD) grain sizes for magnetite particles [e.g. Roberts et al., 1995; Dunlop, 2002]; coercivity values (Bcr) range within 4,24 - 49,95 mT interval (see also Table 1). Slightly open loops and coercivity values within the range of 26,14-41,34 $\mathrm{mT}$ are instead characteristic of the urban samples in Rome (Figure $4 \mathrm{~A}$, Table 1). The magnetic saturation (Ms) is reached, for most of the samples, at about $300 \mathrm{mT}$, indicating the predominance of low coercivity minerals.

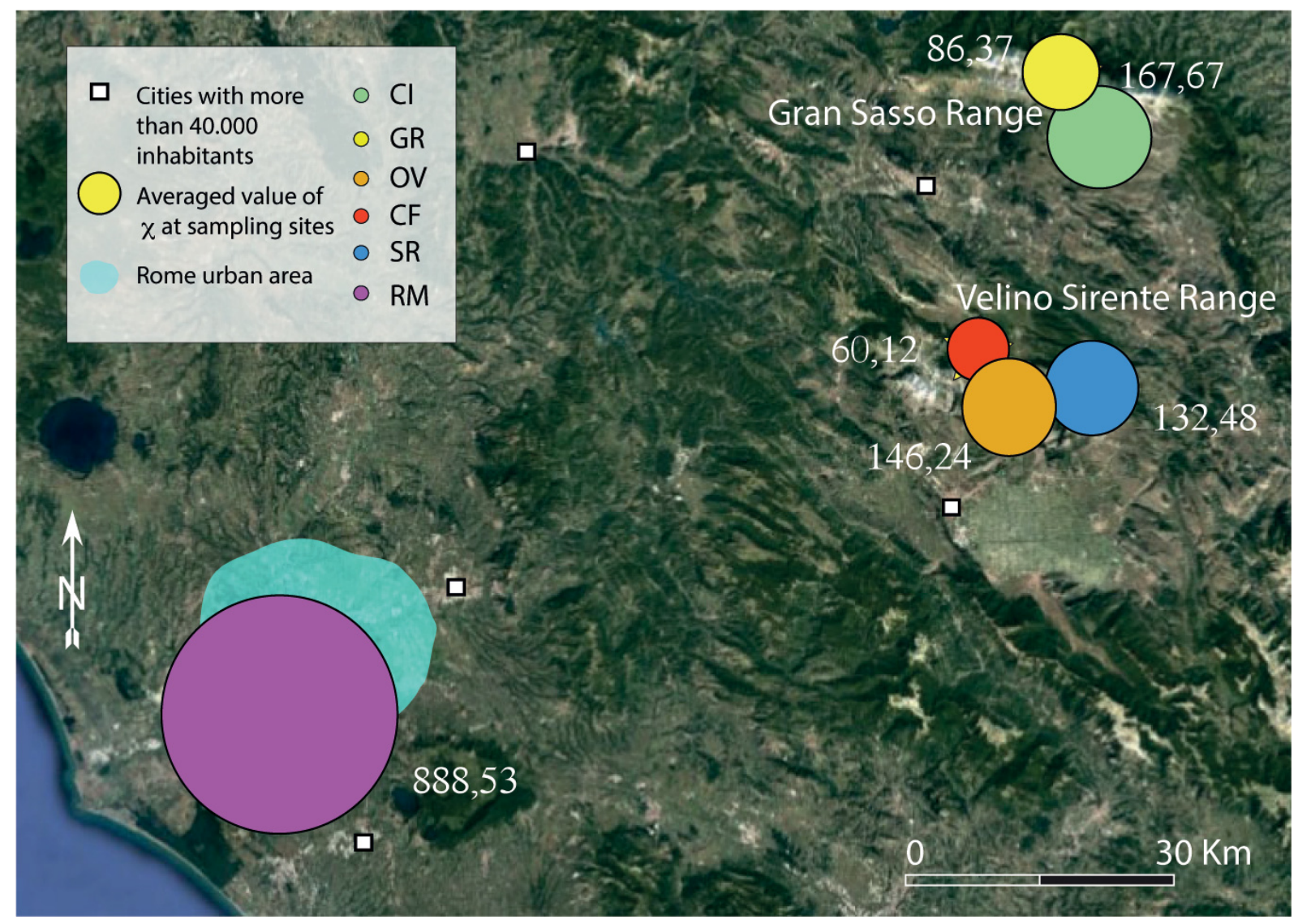

Figure 3. Location of the sampling sites. Colored circles represent the low field mass specific magnetic susceptibility mean value at each site, $\chi$ in $10^{-8} \mathrm{~m}^{3} / \mathrm{kg}$; each circle radius is scaled on $\chi$ magnitude. 


\section{Laura Alfonsi et al.}

\begin{tabular}{|c|c|c|c|c|c|c|}
\hline Site & $\chi\left(10^{-8} \mathrm{~m}^{3} \mathrm{~kg}^{-1}\right)$ & $\operatorname{ARM}\left(\mathrm{Am}^{-1}\right)$ & $\operatorname{SIRM}\left(\mathrm{Am}^{2} \mathrm{~kg}^{-1}\right)$ & $\operatorname{Bcr}(\mathrm{mT})$ & $\operatorname{Sirm} / \chi\left(\mathrm{KAm}^{-1}\right)$ & ARM/SIRM \\
\hline \multicolumn{7}{|l|}{ CI } \\
\hline Min & 20,53 & $3,34 \mathrm{E}-05$ & 4,63E-03 & 5,70 & 8,05 & 0,016 \\
\hline Max & 335,94 & $1,16 \mathrm{E}-04$ & $3,80 \mathrm{E}-02$ & 47,31 & 16,61 & 0,056 \\
\hline mean & 167,78 & 7,20E-05 & $1,77 \mathrm{E}-02$ & 21,50 & 12,70 & 0,036 \\
\hline $\mathrm{Sd}$ & 94,71 & $2,46 \mathrm{E}-05$ & $1,12 \mathrm{E}-02$ & 11,57 & 3,14 & 0,014 \\
\hline \multicolumn{7}{|l|}{ GR } \\
\hline Min & 11,12 & $1,56 \mathrm{E}-05$ & 3,07E-03 & 11,82 & 2,28 & 0,009 \\
\hline Max & 218,42 & $1,09 \mathrm{E}-04$ & $5,37 \mathrm{E}-02$ & 27,66 & 34,29 & 0,052 \\
\hline mean & 86,37 & $6,06 \mathrm{E}-05$ & $1,75 \mathrm{E}-02$ & 21,63 & 10,40 & 0,035 \\
\hline $\mathrm{Sd}$ & 66,62 & 3,39E-05 & 1,90E-02 & 7,08 & 13,79 & 0,018 \\
\hline \multicolumn{7}{|l|}{ OV } \\
\hline Min & 109,78 & $1,61 \mathrm{E}-05$ & $5,45 \mathrm{E}-04$ & 4,24 & 2,28 & 0,008 \\
\hline Max & 175,15 & 9,31E-05 & 3,76E-02 & 49,95 & 34,29 & 0,045 \\
\hline mean & 146,25 & $4,65 \mathrm{E}-05$ & 1,42E-02 & 27,10 & 10,40 & 0,022 \\
\hline $\mathrm{Sd}$ & 27,22 & $3,35 \mathrm{E}-05$ & 1,61E-02 & 18,62 & 13,79 & 0,016 \\
\hline \multicolumn{7}{|l|}{ CF } \\
\hline Min & 20,22 & $1,16 \mathrm{E}-05$ & 1,94E-03 & 4,38 & 0,76 & 0,006 \\
\hline Max & 131,30 & $5,17 \mathrm{E}-05$ & 1,13E-02 & 26,38 & 1,79 & 0,025 \\
\hline mean & 60,12 & $3,01 \mathrm{E}-05$ & $8,88 \mathrm{E}-03$ & 20,24 & 1,17 & 0,013 \\
\hline $\mathrm{Sd}$ & 43,15 & $1,68 \mathrm{E}-05$ & $3,20 \mathrm{E}-03$ & 8,64 & 0,45 & 0,009 \\
\hline \multicolumn{7}{|l|}{ SR } \\
\hline Min & 86,21 & $3,62 \mathrm{E}-05$ & $1,24 \mathrm{E}-02$ & 11,14 & 7,61 & 0,017 \\
\hline Max & 221,71 & 1,29E-04 & $1,84 \mathrm{E}-02$ & 28,59 & 17,92 & 0,062 \\
\hline mean & 132,49 & 9,69E-05 & $1,55 \mathrm{E}-02$ & 20,23 & 11,71 & 0,048 \\
\hline $\mathrm{Sd}$ & 41,80 & $2,99 \mathrm{E}-05$ & $2,34 \mathrm{E}-03$ & 8,29 & 4,46 & 0,018 \\
\hline \multicolumn{7}{|l|}{ RM } \\
\hline Min & 509,02 & 1,63E-01 & $1,15 \mathrm{E}-01$ & 26,14 & 12,37 & 0,097 \\
\hline Max & 1054,60 & $1,12 \mathrm{E}+02$ & 1,62E-01 & 41,34 & 25,12 & 0,538 \\
\hline Mean & 888,54 & $1,44 \mathrm{E}+01$ & 1,33E-01 & 35,38 & 16,33 & 0,285 \\
\hline $\mathrm{Sd}$ & 159,83 & $3,69 \mathrm{E}+01$ & $1,46 \mathrm{E}-02$ & 4,87 & 3,92 & 0,143 \\
\hline
\end{tabular}

Table 1. Minimum, maximum, mean values and standard deviation, for principal magnetic parameters obtained from each site.

The general trend of the thermomagnetic curves enhance a sharp magnetic susceptibility decrease at $580^{\circ}-600^{\circ} \mathrm{C}$, the typical Curie temperature for magnetite, which constitutes the principal contributor to the magnetic susceptibility of our samples. Decreasing between $580^{\circ}$ and $700^{\circ} \mathrm{C}$ have been retrieved only for few samples (CI02, CI06, RM), suggesting the presence of higher coercivity magnetic mineral, as hematite, as accessory mineral (Figure 4 column B). All the samples have irreversible cooling curves, and beside the samples from the urban area, the whole set of the cooling curves are above the heating, implying neoformation of new magnetic phases during the heating process [Hunt et al., 1995; Petrovský and Kapicka, 2006; Jordanova and Jordanova, 2016]. The magnetic susceptibility values plotted versus isothermal remanent magnetization (SIRM) (Figure 5a) illustrate the magnetic concentration and give rough information on the magnetic grain size [Thompson and Oldfield, 1986]. This specific graph holds a good linear relation $\left(\mathrm{R}^{2}=0,91672\right)$, with the increment of magnetic mineral concentration, into the upper right corner, that coincides with the cluster of the Rome urban samples and indicates difference in the content of magnetic minerals rather than changes in the magnetic phases. When the covariance relation subsists, the snow residuals have ferromagnetic minerals dominating the magnetic properties [Urbat et al., 2004]. The upper part of the diagram of Figure 5a corresponds to minerals with high ferromagnetic content and small magnetic grain size, this observation is consistent with Figure 5b, where the samples of RM (urban origin) are placed [Lecoanet et al., 2003]. The majority of the samples bear magnetic grains size of ca. $8 \mu \mathrm{m}$ (Figure 5a), higher dimension are retrieved only for some 

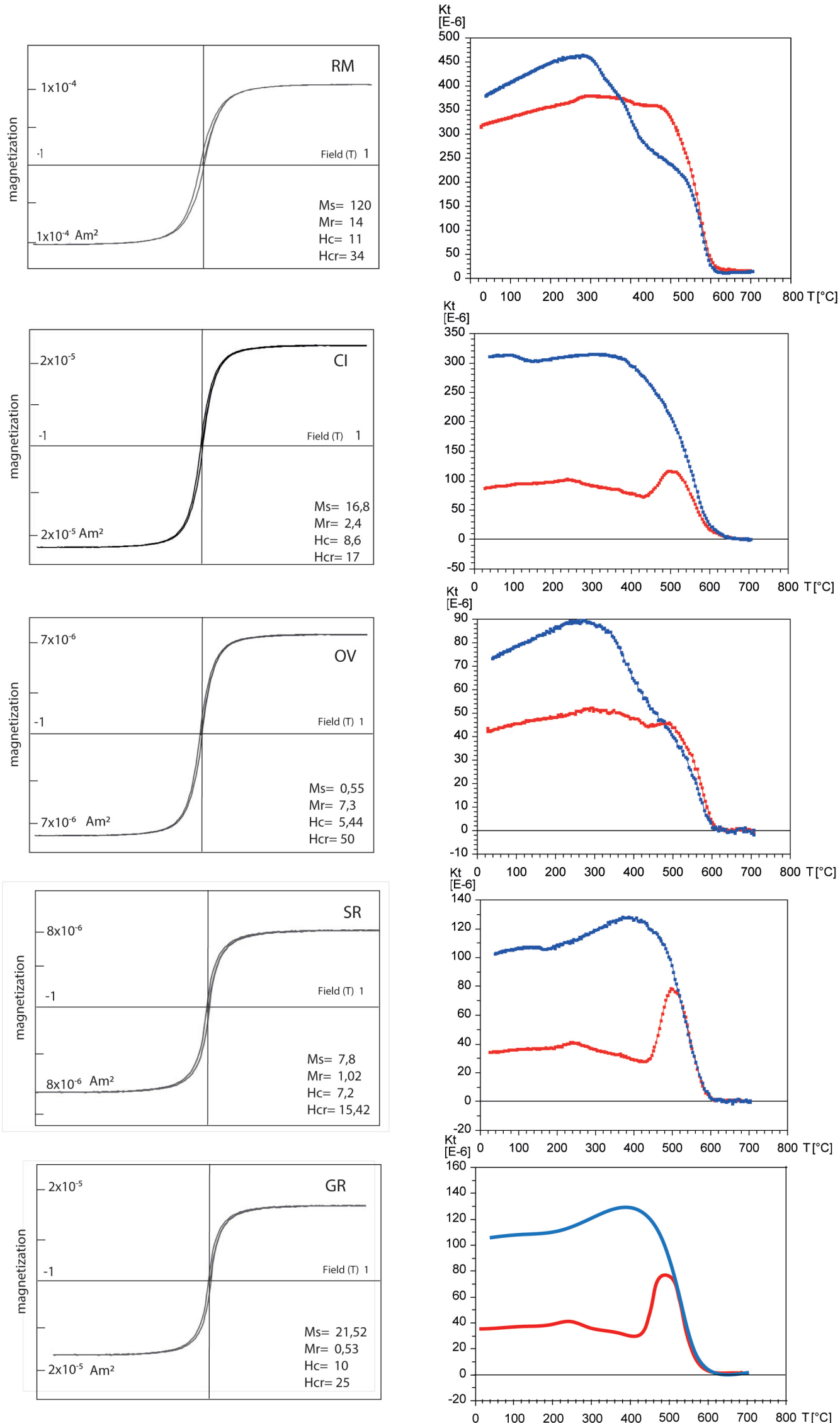

Figure 4. Hysteresis loops for representative sample at each site (column A); corresponding temperature dependent magnetic susceptibility behavior (column B). 


\section{Laura Alfonsi et al.}

sample of the Gran Sasso Range (GR) and at the Ovindoli site (OV). The $8 \mu \mathrm{m}$ mean grain size corresponds to the pseudo single domain state [Dunlop, 2002; Thompson and Oldfield, 1986]. Coupling this latter graph with the one illustrating the inter-parametric ratios that indicates grain size variations (Figure $5 b$ ), it is confirmed that samples with higher magnetic concentration bear particles with the lower grain size dimension, i.e. the ones belonging to the urban area (Figure 5a-b). The remaining specimens, the ones from the non-urban environment, are characterized instead by minor magnetic concentration and greater grain size (Figure $5 \mathrm{~b}$ ). This general behavior is confirmed by the hysteresis parameters data as illustrated in the grain size distribution plot [e.g. Day et al., 1977; Dunlop, 2002] (Figure 5c). Here, the majority of the samples fall in the PSD state area, with some exceptions made for samples falling into the mixing area of single domain (SD)-multi domain (MD) state.
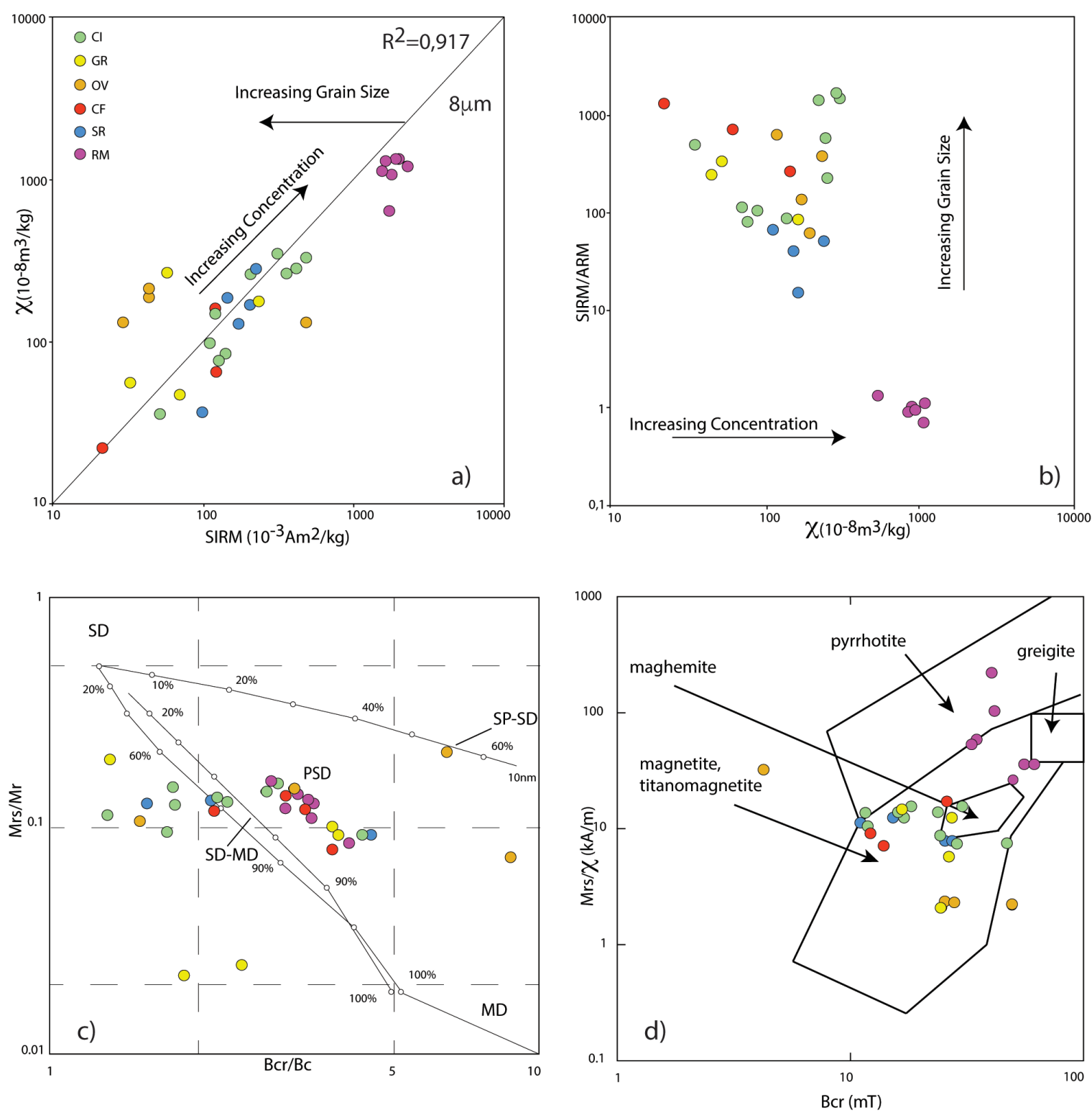

Figure 5. Biplots of (a) magnetic concentration parameters (SIRM versus $\chi$ ); (b) $\chi$ versus grain-size parameters (SIRM/ARM); (c) Hysteresis ratios plotted on a grain size distribution plot [Day et al., 1977; Dunlop, 2002]; (d) biplots of SIRM/ $\chi$ ratio versus Bcr to discriminate magnetic minerals from each other's. Individual polygonal boxes denote the magnetic minerals corresponding domains; label sites as in the legend. SIRM and ARM values are expressed in $10^{-3} \mathrm{Am}^{2} \mathrm{~kg}^{-1}$; magnetic susceptibility $(\mathrm{X})$ is expressed in $10^{-8} \mathrm{~m}^{3} \mathrm{~kg}^{-1}$. SD: single domain; PSD: pseudo-single domain; MD: multi-domain. Concentration and grain size values in (a) and polygonal boxes in (d) following Thompson and Oldfield [1986]. 
The values of Mrs $/ \chi(\mathrm{kA} / \mathrm{m}$ ) plotted versus Bcr (Figure $5 \mathrm{~d}$ ) of our samples fall in the magnetite and titanomagnetite field [Peters and Thompson, 1998]. In the same biplot graph, is evidenced the presence of pyrrhotite (Fel-xS, $0<\mathrm{x}<0.125$ ) for some samples of the urban dusts (RM see Figure $5 \mathrm{~d}$ ). Although, its presence was not confirmed by other rock magnetic analyses (i.e. thermomagnetic curves for Curie temperature).

To resume, the whole set of data and analyses point toward a variability among the studies sites principally related to the magnetic concentration and/or slight differences in grain size, rather than presence of different magnetic mineralogy. As expected, the largest concentration of magnetic minerals is observed in urban area samples, also carried by fine grain size minerals; while coarse grain size is representative for samples of the intermountain sites (CF, CI, OV). On the basis of the above consideration, the site of Rome, positioned along and heavy traffic loaded area, can be considered as a reference site for a "polluted" area with respect of the whole set of analyzed samples.

The FESEM analysis allowed the recognition of Fe-rich particles in the samples. It should be noted that, because of an analytical problem in the spectra, it was not possible to acquire the signal of the light elements, under oxygen. The major element identified in the analyzed particles is mainly Fe with minor contribution at some sample of Ti (observed at the OV site). The analysis indicates that the magnetic minerals of the samples are predominantly represented by Fe-oxides (i.e. magnetite, Table 2).

\begin{tabular}{|c|c|c|c|c|c|c|c|c|c|c|c|c|}
\hline Sample & MgO & $\mathrm{Al}_{2} \mathrm{O}_{3}$ & $\mathrm{SiO}_{2}$ & $\mathbf{P}_{2} \mathbf{O}_{5}$ & $\mathrm{~K}_{2} \mathrm{O}$ & $\mathrm{CaO}$ & $\mathrm{Ag}_{2} \mathrm{O}$ & $\mathrm{La}_{2} \mathrm{O}_{3}$ & $\mathrm{CeO}_{2}$ & $\mathrm{TiO}_{2}$ & FeO & TOT \\
\hline OV01_1 & 1,32 & 5,42 & 1,08 & & & 0,86 & & & & 12,66 & 78,66 & 100,00 \\
\hline OV01_2 & 1,00 & 3,37 & 0,75 & & & 1,61 & & & & 11,57 & 81,70 & 100,00 \\
\hline OV01_3 & 1,58 & 4,08 & 1,27 & & & 1,00 & & & & 9,20 & 82,87 & 100,00 \\
\hline OV01_4 & 0,90 & 4,02 & 2,27 & & & 1,69 & & & & 9,85 & 81,27 & 100,00 \\
\hline OV01_5F & 8,19 & 4,82 & 54,15 & & 2,04 & 20,24 & & & & & 10,56 & 100,00 \\
\hline OV01_5 & & 1,42 & 19,69 & 15,16 & & 36,69 & 5,07 & 7,76 & 14,21 & & & 100,00 \\
\hline Gr06_S & 1,65 & 16,98 & 25,13 & & 1,43 & 0,62 & & & & & 54,19 & 100,00 \\
\hline GR06_S & & 23,70 & 35,18 & & 3,63 & & & & & & 37,50 & 100,00 \\
\hline GR06_T & 1,65 & 16,98 & 25,13 & & 1,43 & 0,62 & & & & & 54,19 & 100,00 \\
\hline SR02_1 & 6,15 & 22,04 & 29,68 & & & & & & & & 42,13 & 100,00 \\
\hline SR02_2 & 1,92 & 7,52 & 14,83 & 1,05 & 0,62 & & & & & & 74,06 & 100,00 \\
\hline SR02_S & 2,27 & 14,10 & 20,61 & 3,32 & 0,87 & & & & & & 58,83 & 100,00 \\
\hline
\end{tabular}

Table 2. Chemical composition (oxides weight \%) obtained by FESEM-EDS microanalysis from Fe-rich particles collected in three different natural protected areas of the Central Apennines. See text for discussion. Light elements (under O) were not analyzed due to contamination of EDS detector

The SEM-EDS also indicates a distinctive morphological aspect associated to a specific chemical composition. In particular, magnetic particles with spherical shape and porous aggregates have predominance of $\mathrm{Fe}$ and $\mathrm{O}$ accompanied with $\mathrm{Ti}$, which is typical for particles originated from fast cooling of melts or as result of combustion of fossil fuel [e.g. Flanders, 1994, 1999]. The morphological and elemental characteristic or the magnetic particles of 


\section{Laura Alfonsi et al.}

some of the analyzed samples (RM, OV), allows to attributed them an anthropogenic origin [Strzyszcz et al., 1996; Veneva et al., 2004; Sagnotti et al., 2006, 2009; Petrovský et al., 2013; Liu et al., 2019]. The SED-EDS observation confirmed that the site of Rome bears grains size with finer particles, and these in general are in the range of $50 \mathrm{~nm}$ - $1 \mu \mathrm{m}$ dimension (Figure 6a); this finer spherical particles are mainly anthropogenic iron-rich sphere. Instead, larger grains, with dimension $>1$ micron, are more frequent at the intermountain sites (Figure 6b, c, d); although magnetite fine particles, even if sparse, have been retrieved also at these sites (Figure 6e). Silica-aluminum sphere are also present at almost all the sites, these quartz spherules of air blow aeolian dust, are probably of Saharan origin [see Sagnotti et al., 2006]. At the Rome site, these are often coated with ferromagnetic particles of nano-dimensions.

The mass percentage oxides composition of some the analyzed samples, containing ferro oxides, is summed in Table 2. GR and SR samples contain a high percentage of Si and Al, while OV samples show reduced quantities of these elements. All the particles coming from the OV area show high Fe levels with ca. 10\% of Ti content, these samples come from a parking slot in a ski resort facility. In this locality other non-magnetic anthropogenic pollutants have been found: mainly products of fertilization compounds, and remains of component employed in abrasive materials (Cerium oxides). Finally, all the analyzed samples show low percentage contents of other cations such as $\mathrm{Mg}, \mathrm{Ca}$, $\mathrm{K}$, and $\mathrm{P}$.

It should be noted that, although the FESEM-EDS analysis pointed to a non-neglectable amount of Ti in some samples (up to $10 \%$ in the OV site cfr. Table 2), this does not find correspondence in the Curie temperature of the selected samples measured: no clear peak of susceptibility at $530^{\circ} \mathrm{C}$ is visible in the heating curve [Evans and Heller, 2003], pointing instead to pure magnetite as the lonely magnetic carrier (Figure $4 \mathrm{~b}$ ). The same consideration holds for the presence of pyrrhotite in some of the samples at the RM site (cfr Figure 5d), whose existence it is not manifested in the corresponding thermomagnetic curve (Figure 4a). This may appear as a discrepancy, but it should be considered that the resolution of the EDS-FESEM analysis in on the order of nanometers and directly carried on the selected particle, while the K-T determination is made on the bulk material. Moreover, at least for the Rome site the samples utilized for the thermomagnetic analysis are the ones falling in the pure magnetite field in grain size distribution plot (Figure 5d).

\section{Conclusion}

This study made a comparison among rock magnetic data obtained from snow deposits in wilderness areas in central Italy and in the urban center of Rome, allowing to identify the characters and the origin of the magnetic particulate matter. Results indicate that: i) in both areas from rock magnetic properties the ferromagnetic content of the PM is mainly represented by magnetite; ii) the difference among sites refers to concentrations of the magnetic minerals, rather that mineralogical differentiation; iii) chemical analysis and particulate morphology, coupled with magnetic measurements (concentration and grain size), highlighted the differences between natural or anthropogenic origin of minerals.

As a general result, the study disclosed that anthropogenic derived magnetic particles are abundant in areas where local sources of pollution are permanently active, such as high traffic urban roads, and/or have seasonal activity (i.e. parking lots of ski resort facilities). In the isolated and protected natural park area, the anthropic magnetic contribution is very low and associated with the prevalent natural component.

The rock magnetic analysis presented, coupled with FESEM observations, demonstrated to be a valuable additional method to define local pollution, suitable to define the source of the related material in different environments. In this respect, the snow is confirmed to be a valid neutral collecting tool to investigate and monitor the particulate matter.

The monitoring of particulate matter has an important role in human health preservation, the results of this paper confirmed that snow can be employed to that purpose also in those areas where no automatic monitoring facilities are available, and/or where snow constitutes the main precipitation. These kind of studies should be prosecuted in order to ameliorate and standardize their feasibility and procedures.

Acknowledgements. We ought to thank the two anonymous reviewers, their careful corrections and advices significantly ameliorated the whole structure and development of the paper. 
Rock magnetism on snow stacks in central Italy
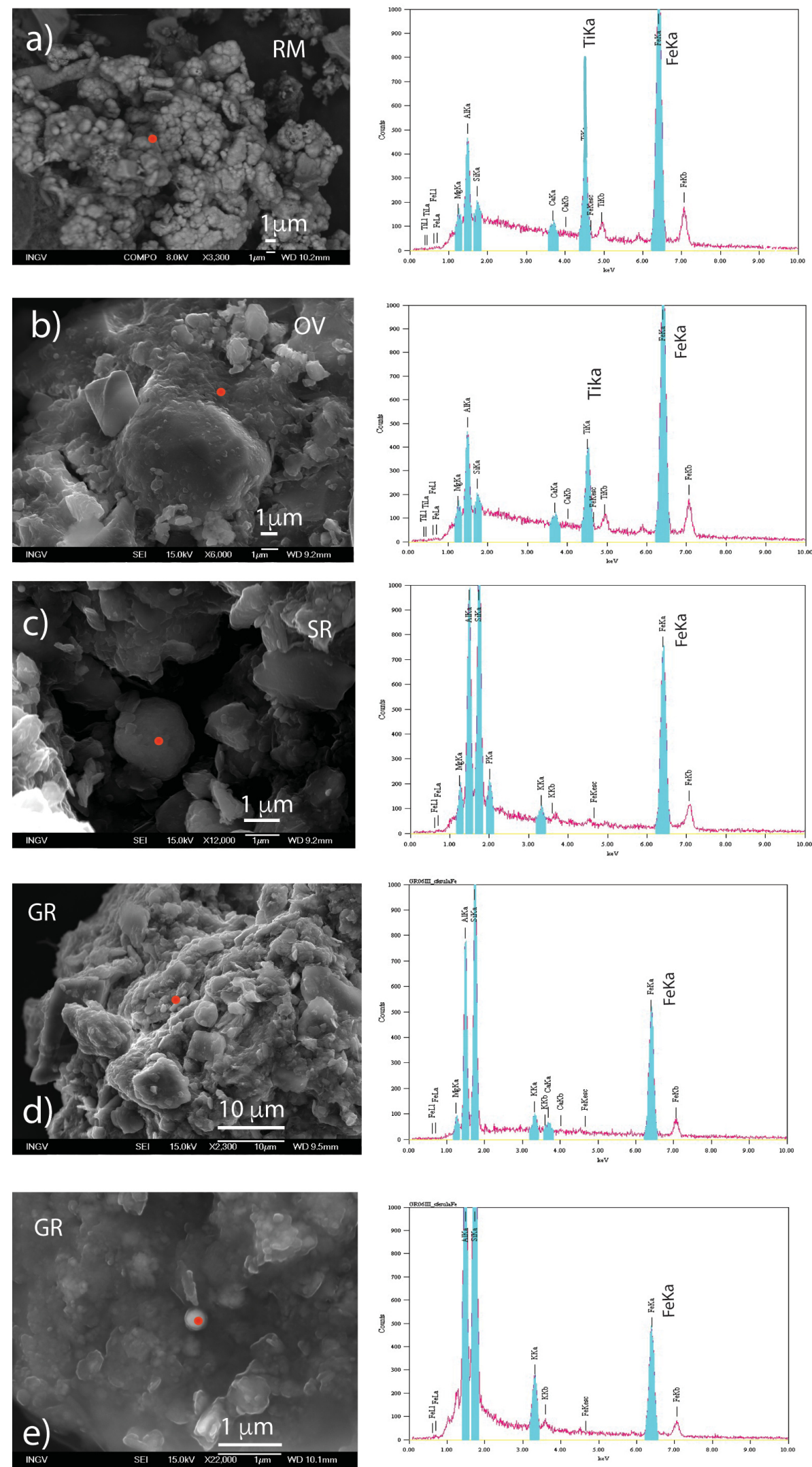

Figure 6. FESEM images of analyzed Fe-rich PM (red dots) and corresponding EDS spectra for: (a) Road dusts, anthropogenic Ti-reach magnetite aggregates, RM site; (b) Ti-reach magnetite OV site; (c) anthropogenic Fe-oxides SR site; (d) aggregates of Fe-Oxides, and aeolian sands in Sr site (e) sand granule, probably eolian wind-blown dust at GR site. 


\section{Laura Alfonsi et al.}

\section{References}

Abas, A. (2021). A systematic review on biomonitoring using lichen as the biological indicator: A decade of practices, progress and challenges, Ecological Indicators, 121, doi.org/10.1016/j.ecolind.2020.107197.

Boom, A., J. Marsalek (1988). Accumulation of polycyclic aromatic hydrocarbons (PAHs) in an urban snowpack, Sci. Total Environ., 74, 133-148.

Búcko, M.S., T. Magiera, B. Johansond, E. Petrovský and L.J. Pesonen (2011). Identification of magnetic particulates in road dust accumulated on roadside snow using magnetic, geochemical and micro-morphological analyses, Environ. Pollut., 5, 1266-1276.

Conti, M.E., G. Cecchetti (2001). Biological monitoring: lichens as bioindicators of air pollution assessment $-\mathrm{a}$ review, Environ. Pollut., 114, 3, 471-492.

Day, R., M. Fuller and V. Schmidt (1997). Hysteresis properties of titanomagnetites: grain-size and compositional dependence, Phys. Earth Planet. Inter., 13, 260-267.

Dunlop, D.J. (2002). Theory and application of the Day plot (Mrs/Ms versus Hcr/Hc): 1. Theoretical curves and tests using titanomagnetite data, J. Geophys. Res., 107(B3), 2056, doi:10.1029/2001JB000486.

Elìk, A. (2002). Monitoring of Heavy Metals in Urban Snow as Indicator of Atmosphere Pollution, Int. J. Environ. Analyt. Chem. 82, 1, 37-45, doi:10.1080/03067310290024085.

Engelhard, C., S. De Toffol, I. Lek, W. Rauchand and R. Dallinger (2007). Environmental impacts of urban snow management the alpine case study of Innsbruck, Sci. Total Environ., 382, 286-294.

Evans, M.E. and F. Heller (2003). Environmental Magnetism - Principles and Applications of Enviromagnetics, Geophys. J. Int., 158, 2004, 1177-1178.

Flanders, P. (1994). Collection, measurement, and analysis of airborne magnetic particulates from pollution in the environment (invited), J. Appl. Phys., 75, 5931.

Flanders, P. (1999). Identifying fly ash at a distance from fossil fuel power stations, Environ. Sci. Technol., 33, 528-532.

Gabrielli, P., G. Cozzi, S. Torcini, P. Cescon and C. Barbante (2008). Trace elements in winter snow of the Dolomites (Italy): a statistical study of natural and anthropogenic contributions, Chemosphere 72, 1504-1509.

Gieré, R. (2016). Magnetite in the human body: Biogenic vs. anthropogenic, Proceedings of the National Academy of Sciences Oct 2016, 113, 43, 11986-11987, doi:10.1073/pnas.1613349113.

Hunt, C. P., B. M. Moskowitz and S. K. Banerjee (1995). Magnetic properties of rocks and minerals, Rock Phys. Phase Relat Hand, Phys. Constants AGU Ref. Shelf 3, 189-204.

Jordanova, D. and N. Jordanova (2016). Thermomagnetic Behavior of Magnetic Susceptibility-Heating Rate and Sample Size Effects. Front. Earth Sci. 3:90. doi: 10.3389/feart.2015.00090.

Kodnik, D., A. Winkler, F. Candotto Carniel and M. Tretiach (2017). Biomagnetic monitoring and element content of lichen transplants in a mixed land use area of NE Italy, Sci Total Environ, 595, 858-867.

Kuoppamaki, K., H. Setala, A.L. Rantalainen and D.J. Kotze (2014). Urban snow indicates pollution originating from road traffic, Environ. Pollut., 195, 56-63.

Lecoanet, H., F. Leveque and J.P. Ambrosi (2003). Combination of magnetic parameters: an efficient way to discriminate soil contamination sources (south France), Environ. Pollut., 122, 229- 234.

Liu, H., Y. Yan, H. Chang, H. Chen, L. Liang, X. Liu, X. Qiang and Y. Sun (2019). Magnetic signatures of natural and anthropogenic sources of urban dust aerosol, Atmos. Chem. Phys., 19, 731-745.

Maher, B.A., I.A., Ahmed, V. Karloukovski, D.A. MacLaren, P.G. Foulds, D. Allsop, D.M. Mann, R. Torres-Jardón and L. Calderon-Garciduenas (2016). Magnetite pollution nanoparticles in the human brain, Proc. Natl. Acad. Sci. U. S. A. 2016 Sep 27, 113(39), 10797-801.

Marié, D.C., M.A.E. Chaparro, A.M. Sinito, and A. Lavat (2020). Magnetic biomonitoring of airborne particles using lichen transplants over controlled exposure periods: SN, Applied Science, 2, 104.

Moreno, E., L. Sagnotti, J. Dinarès-Turell, A. Winkler and A. Cascella (2003). Biomonitoring of traffic air pollution in Rome using magnetic properties of tree leaves, Atmos. Environ., 37, I, 21, 2967-2977.

Müller A., H. Österlund, J. Marsalek and M. Viklander (2020). The pollution conveyed by urban runoff: A review of sources, Sci. Total Environ., 709, doi.org/10.1016/j.scitotenv.2019.136125.

Nazarenko, L., D. Rind, K. Tsigaridis, A.D. Del Genio, M. Kelley and N. Tausnev (2017). Interactive nature of climate change and aerosol forcing, J. Geophys. Res. Atmos., 122, 6, 3457-3480, doi:10.1002/2016JD025809. 
Oberdörster, G., Z. Sharp, V. Atudorei, A. Elder, R. Gelein, W. Kreyling and C. Cox (2004). Translocation of inhaled ultrafine particles to the brain, Inhal Toxicol., 2004 Jun 16, 6-7, 437-45.

Paoli, L., A. Winkler, A. Guttová, L. Sagnotti, A. Grassi, A. Lackovicovà, D. Senko and S.Loppi (2017). Magnetic properties and element concentrations in lichens exposed to airborne pollutants released during cement production, Environ. Sci. Pollut. Res., 24, 12063-12080.

Pankhurst, Q., D. Hautot, N. Khan and J. Dobson (2008). Increased levels of magnetic iron compounds in Alzheimer's disease, J. Alzheimer's Dis., 13, 1, 49-52, doi:10.3233/jad-2008-13105.

Peters, C. and R. Thompson (1998). Magnetic identification of selected natural iron oxides and sulphides, J. Magn. Magn. Mater., 183, 3, 365-374.

Petrovský, E. and A. Kapicka (2006). On determination of the Curie point from thermomagnetic curves, J. Geophys. Res., 111, B12S27, doi:10.1029/2006JB004507.

Petrovský, E., R. Zbořil, T.M. Grygar, B. Kotlík and J. Novák (2013). Magnetic particles in atmospheric particulate matter collected at sites with different level of air pollution, Stud. Geophys. Geod., 57, 755-770, doi.org/10.1007/s11200-013-0814-x.

Roberts, A.P., Y. Cui, and K.L. Verosub (1995). Wasp-waisted hysteresis loops: Mineral magnetic characteristics and discrimination of components in mixed magnetic system, J. Geophys. Res., 100, 17,909-17,924.

Sagnotti, L., P. Macrì, R. Egli and M. Mondino (2006). Magnetic properties of atmo- spheric particulate matter from automatic air sampler stations in Latium (Italy): toward a definition of magnetic fingerprints for natural and anthropogenic PM10 sources, J. Geophys. Res., 111, B12S22, doi:10.1029/ 2006JB004508.

Sagnotti, L., J. Taddeucci, A. Winkler and A. Cavallo (2009). Compositional, morphological, and hysteresis characterization of magnetic airborne particulate matter in Rome, Italy, Geochem. Geophys. Geosyst., 10, Q08Z06, doi:10.1029/2009GC002563.

Strzyszcz, Z., T. Magiera and F. Heller (1996). The influence of industrial emissions on the magnetic susceptibility of soils in Upper Silesia, Studia Geophys. Geod., 40, 276-286.

Thompson, R. and F. Oldfield (1986). Environmental Magnetism, Allen and Unwin: Springer, London, doi.org/10.1007/978-94-011-8036-8.

Urbat, M., E. Lehndorff and L. Schwark (2004). Biomonitoring of air quality in the Cologne conurbation using pine needles as a passive sampler-Part I: magnetic properties, Atmos. Environ., 38, 3781- 3792.

Veneva, L., V. Hoffmann, D. Jordanova, N. Jordanova and T. Fehr (2004). Rock magnetic, mineralogical and microstructural characterization of fly ashes from Bulgarian power plants and the nearby anthropogenic soils, Phys. Chem. Earth, 29, 1011-1023.

Viklander, M., (1996). Urban snow deposits e pathways of pollutants, Sci. Total Environ., 189/190, 379-384.

Viskari, E.L., R. Rekila, S. Roy, O. Lehto, J. Ruuskanen and L. Karenlampi (1997). Airborne pollutants along a roadside: Assessment using snow analyses and moss bags, Environ. Pollut., 97, I 1-2, 153-160.

Westerlund, C. and M. Viklander (2006). Particles and associated metals in road runoff during snowmelt and rainfall, Sci. Total Environ, 362, 1-3, 143-156.

Winkler A., C. Caricchi, M. Guidotti, M. Owczarek, P. Macrì, M. Nazzari, A. Amoroso, A. Di Giosa and S. Listrani (2019). Combined magnetic, chemical and morphoscopic analyses on lichens from a complex anthropic context in Rome, Italy. Sci. Total Environ., 690, 1355-1368.

Winkler A., T. Contardo, A. Vannini and S. Sorbo (2020). Magnetic Emissions from Brake Wear are the Major Source of Airborne Particulate Matter Bioaccumulated by Lichens Exposed in Milan (Italy), Appl. Sci., 10, 6, 2073. 